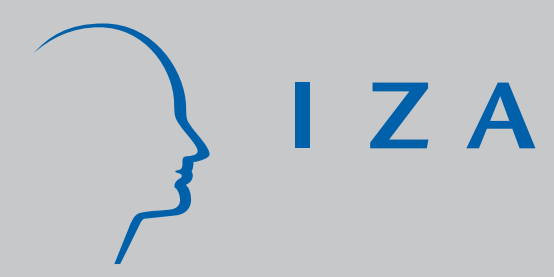

IZA DP No. 2379

Telecommunications Dynamics, Output and Employment

Andre J ungmittag

Paul J.J. Welfens

October 2006 


\title{
Telecommunications Dynamics, Output and Employment
}

\author{
Andre Jungmittag \\ University of Wuppertal \\ Paul J.J. Welfens \\ University of Wuppertal \\ and IZA Bonn
}

Discussion Paper No. 2379
October 2006

\author{
IZA \\ P.O. Box 7240 \\ 53072 Bonn \\ Germany \\ Phone: +49-228-3894-0 \\ Fax: +49-228-3894-180 \\ E-mail: iza@iza.org
}

\begin{abstract}
Any opinions expressed here are those of the author(s) and not those of the institute. Research disseminated by IZA may include views on policy, but the institute itself takes no institutional policy positions.

The Institute for the Study of Labor (IZA) in Bonn is a local and virtual international research center and a place of communication between science, politics and business. IZA is an independent nonprofit company supported by Deutsche Post World Net. The center is associated with the University of Bonn and offers a stimulating research environment through its research networks, research support, and visitors and doctoral programs. IZA engages in (i) original and internationally competitive research in all fields of labor economics, (ii) development of policy concepts, and (iii) dissemination of research results and concepts to the interested public.
\end{abstract}

IZA Discussion Papers often represent preliminary work and are circulated to encourage discussion. Citation of such a paper should account for its provisional character. A revised version may be available directly from the author. 
IZA Discussion Paper No. 2379

October 2006

\begin{abstract}

\section{Telecommunications Dynamics, Output and Employment}

In EU countries, opening up of telecommunications markets and regulations have helped to reduce the price of digital services which is an important quasi-input factor in all firms. Integrating the use of telecommunications in a macroeconomic production function is the analytical starting point for our interdependent analysis of output, use of telecommunications and employment. Based on unit root and co-integration analysis as well as an error correction three-equation model which are estimated simultaneously, we present results both on long run links and short run links between telecommunications, output and employment. Considering various scenarios suggests that a fall in the relative price of telecommunications can generate a cumulated employment increase of 760,000 within seven years in Germany. The institutional setup for regulating telecommunications could be improved in Germany and other EU countries.
\end{abstract}

JEL Classification: E0, L96, O0

Keywords: telecommunications, employment, growth, knowledge society, regulation

Corresponding author:

Paul J.J. Welfens

European Institute for International Economic Relations (EIIW)

University of Wuppertal

Rainer-Gruenter-Str. 21

D-42119 Wuppertal

Germany

E-mail:welfens@eiiw.uni-wuppertal.de 


\section{Telecommunications Dynamics, Output and Employment}

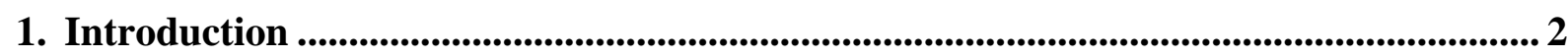

2. Telecommunications, Employment and Output: Model and Empirical Analysis.......... 4

2.1. Estimation of the Long Run Relationships.............................................................. 4

2.2. Estimation of the Dynamic Simultaneous Error Correction Model ....................... 6

2.3. Selected Scenarios ................................................................................................................... 8

3. Policy Implications ........................................................................................................... 13

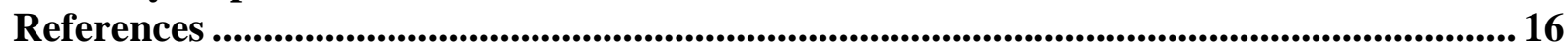




\section{Introduction}

Economic developments and innovations are influenced by the interplay of competition and technological dynamics. The growth of information and communication technology (ICT) has strongly contributed to investment and growth in the US and many EU countries (e.g. AUDRETSCH/WELFENS, 2002). The European Commission has emphasized in its policies and particularly in its Lisbon Agenda of 2000 that developing a dynamic EU knowledge society in which information is a distinct element of the production function will be important; telecommunications services are relevant in this perspective. The EU has opened up telecommunications markets in 1998 and thus reinforced competition in this sector. In a more general approach the theoretical and empirical analysis of BAYOUMI/LAXTON/PESENTI (2004) indicates that Europe would benefit from more competition, and more competition in network industries including telecommunications is of key importance here. More intensive competition in telecommunications which is capital intensive could help in enjoying efficiency gains in investment, but it would also stimulate sector growth through network effects and would simultaneously reduce costs in sectors using telecommunications services as an input.

Telecommunications services are a key element of ICT. Innovative services help to reduce transaction costs and stimulate networking in the business community. Digital goods also offer many options for product differentiation. Falling relative prices generate additional demand. Volume growth, which partly benefits from network effects on the demand side - endogenous growth of demand -, in turn, raises investment needs. There is broad consensus that ICT production stimulated growth in the US and Europe in the 1990s, but growth accounting (VAN ARK/PIATKOWSKI, 2004) also suggests that the use of telecommunications is important for output expansion in Europe, both in Eastern and in Western Europe.

Moreover, as information is an input in all sectors, the cheaper use of telecommunications and the launching of advanced digital services will stimulate output growth. From a macroeconomic perspective, one may argue that broader and faster communication networks including mobile telecommunications stimulates output growth through faster diffusion of knowledge. Indeed there is empirical evidence for Germany (JUNGMITTAG/WELFENS, 1996) which shows that not only capital and labour inputs in addition to technology inputs - proxied by patents and real expenditures for imported licences - contribute to output growth, but the number of telecommunications calls does so as well. The authors estimate a long run production function for the period 1970-1990 for Germany. RÖLLER/WAVERMANN (1996; 1996a) and CANNING (1999) have used telecommunications density as one of the inputs in explaining growth for a panel of countries in the period 1970-1990 and 1960-90, respectively. Other authors have also provided some empirical evidence on the link between telecommunications and growth (CRONIN/COLLER/HERBERT et al. 1993; CRONIN/PARKER/COLLERAN et al. 1993; KARUNARATNE, 1997). An important issue in modern growth analysis is the explanation of technological progress, whereby a standard reference is MANKIW/ROMER/WEIL (1992); more sophisticated approaches have been presented by several authors (BUDD/HOBBIS, 1989; 1989a; COE/MOGHADAM, 1993; JUNGMITTAG/WELFENS, 1996; JUNGMITTAG/BLIND/GRUPP; 1999). Subsequent analysis is partly based on this work, in particular JUNGMITTAG/WELFENS, 1996; RÖLLER/WAVERMANN, 1996 and 1996a and CANNING, 1999): A dynamic, 
simultaneous, multi-equation approach for Germany is presented so that we can analyze the links between telecommunications, growth and employment; simulations can also be run. Based on unit-root analysis and cointegration analysis, we can analyze both long run dynamics and short-run dynamics. As a first step - based on cointegration analysis - we present a long run production function and demand functions for labour and telecommunication calls. In a second step, we present a simultaneous dynamic, threeequation model for the short run dynamics while taking into account the deviations from long run equilibrium values (error correction model). Basically the spirit of the model is neoclassical, which is in a similar vein as HANSEN (1992; 1993); the latter, however, puts his focus on the interdependence between exogenous technological progress, innovation output indicators and telecommunication calls as a proxy for information and communication. As such, he implicitly considers technological progress.

From a theoretical perspective, it is clear that the relative price of telecommunications services determines the use of information as an input variable in the production process. Price dynamics in turn depend on the case of fixed line networks on regulatory policies. Price caps have been adopted in most EU countries after the start of EU-wide liberalization in 1998. In network industries, government can indeed affect investment and innovation in many ways as has become obvious in the context of the deregulation of fixed network telecommunications in the EU. RPI minus X has become a standard price cap approach in the regulation of telecommunications. That is, regulation estimates sector productivity growth $\mathrm{X}$ and requires a bundle of services - basically the use of essential facilities by other operators - that the dominant firm must not exceed with its regulated basket of prices, the inflation rate (as measured by the retail price index) minus $\mathrm{X}$. This is an incentive regulation since the firm can appropriate any profits stemming from productivity growth beyond $\mathrm{X}$. These regulation-induced price reductions are in line with the more general trend of falling relative prices in information and communication technology.

There is no doubt that technological progress in the production of ICT goods is high, which implies high productivity and output growth in the ICT producing sector. The high rate of technical progress in the ICT producing sector reduces the relative price of ICT investment goods and therefore stimulates accumulation of such investment goods. The relative price fell by about 8\% p.a. in the US and France in the period from 1970 to 1991. From 1991 to 1999, relative price fell by about 15\% in the US but only by about $10 \%$ in France during the same period. In Germany, the producer prices of the OCM industry (OCM=office, computing and accounting machinery) fell by only $1.2 \%$ p.a. in $1970-91$ and 4.4\% p.a. in 1991-99 (Falk/Koebel, 2004). This might partly explain the relatively modest IT-investment-GDP ratio in Germany as compared to leading EU countries and the US. In the US, the total stock of quality-adjusted computer equipment in constant prices increased with a growth rate of $20 \%$ over several years with its peak of about $30 \%$ p.a. in the 1990s (Jorgensen/Stiroh, 2000; Jorgensen/Ho/Stiroh (2002)).

In the following analysis we first present the modelling approach (section 2) before we turn to the key policy conclusions which concern regulatory policies in telecommunications at both the national level and the EU level. At the bottom line, it can be shown that output, aggregate labour demand and the use of telecommunications are interdependent and that the institutional setup in the field of regulations can strongly influence the use of telecommunications. Given Germany's weakness in terms of output growth and employment dynamics, one may argue that careful regulation of telecommunications with clear emphasis on an institutional setting that gives incentives for digital innovations and investment is a key element for raising aggregate real income and employment. 


\section{Telecommunications, Employment and Output: Model and Empirical Analysis 1}

The model developed here carefully considers long term and short term interdependencies between aggregate output, employment and the use of telecommunications. As endogenous variables we consider real income (Y; GDP in constant prices of 1995), the number of gainfully employed $(L)$ and the number of telecommunication calls $(T C)$, whereas data for the latter are based on data from Germany's Federal Statistical Office or from Deutsche Telekom AG. The number of telecommunication calls is considered to be an adequate indicator variable for the diffusion of digital information. While one might want to consider alternative indicator variables, it is clear that only the number of telecommunication calls is available over an extended period. With respect to future modern telecommunications services, one may raise doubts that the number of telecommunications calls is an ideal indicator since the increasing use of the internet protocol in data transmission and voice telephony (VOIP) suggests that the intensity of digital information exchange could be better covered by some other measure for data traffic. We use as exogenous variables the net capital stock ( $K$; in constant prices of 1995) as well as indices for nominal wage costs per capita (WAGE) and the price index of GDP $(P G D P)$. Wage costs as well as the price for telecommunications are considered relative to the GDP deflator with data being derived from the EU's AMECO data bank. Moreover, we use the "average stock of patents" at the German Patent Office as an exogenous indicator for the level of technology. The stock at year end is defined as:

stock at beginning of year + granted (basic) patents + granted additional patents cancelled patents - lapsed patents. ${ }^{2}$

The average stock of patents is one-half the stock of patents in the previous year and the stock at the end of the current year. Using patents registered as an indicator of innovativeness can be justified on various grounds (GRUPP, 1997; JUNGMITTAG, 2002); it can be considered for a number of reasons as a superior indicator compared to R\&D expenditures.

\subsection{Estimation of the Long Run Relationships}

Before the estimation of the long-term relations, we checked whether the considered time series are integrated by the order of 1 (i.e., the series are characterised by unit roots) or whether they follow deterministic trends by ADF tests. The null hypothesis of a unit root cannot be rejected for any of the seven variables. For the first differences ( $\Delta$ is the

1 A comprehensive presentation of the methodology used and the empirical results can be found in Welfens/Zoche/Jungmittag (2005), Internet Economy 2010/Internetwirtschaft 2010, Heidelberg: Springer (study for the German Ministry of Economics and Labor).

2 The patent data from 1963 to 2001 were taken from the Statistical Yearbook of the Federal Statistics Office and from the "Blatt für Patent-, Muster- und Zeichenwesen". The previous non-available values were calculated on the basis of a linear trend estimate. 
differences operator), the null hypothesis must be rejected at a significance of at least $1 \%$. So, it can be concluded that all individual time series are I(1).

The estimation of the long-term production function for Germany from 1960 until 2000 is based on a Cobb-Douglas function, augmented by the number of telephone calls and the patent stock:

(1) $Y_{t}=A \cdot K_{t}^{\alpha} \cdot L_{t}^{\beta} \cdot T C_{t}^{\gamma} \cdot P A T_{t}^{\delta}$,

where $Y_{t}$ represents the output, $K_{t}$ the capital stock, $L_{t}$ labour, $T C_{t}$ the number of telephone calls and $P A T_{t}$ the stock of patents granted at the German Patent Office. The parameters $\alpha$ and $\beta$ represent the partial production elasticities of capital and labour. Furthermore, the interplay of $A, T C_{t}$ and $P A T_{t}$ can be interpreted as a technical progress function, explaining the increase of efficiency. The efficiency parameter $A$ measures exogenous technical progress, while the indicator variables $T C_{t}$ raised to the power $\gamma$ and $P A T_{t}$ raised to the power $\delta$ measure the degree of efficiency due to knowledge diffusion and the stock of results from research and development activities (innovations). In logarithmic form the production function can be written as

(2) $y_{t}=a+\alpha \cdot k_{t}+\beta \cdot l_{t}+\gamma \cdot t c_{t}+\delta \cdot p a t_{t}$,

with lower case letters denoting logarithms.

For the OLS estimation, the production function was supplemented by some dummy variables and a stochastic error term $u_{1 t}$. The first three dummy variables are $D O C$, which captures the shock due to the first oil price crisis, and D80 as well as D81, which capture a structural break starting in 1980 and reinforcing in 1981 following the second oil price crisis. Furthermore, a dummy variable $D G U$ is added to catch the effects of German unification, and D99 for a renewed structural break subsequent to 1999. Then, we get the following long-term production function for Germany from 1960 to 2000:

$$
\begin{aligned}
& y_{t}=-0.590+0.620 k_{t}+0.867 l_{t}+0.095 p a t_{t}+0.119 t c_{t}-0.019 D O C
\end{aligned}
$$

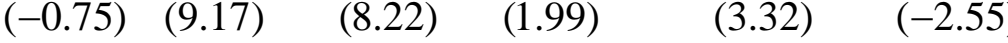

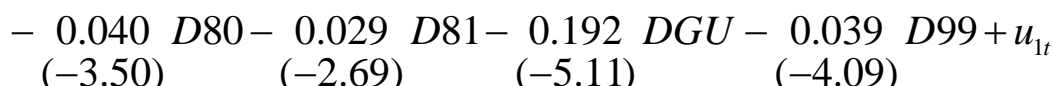

$$
\begin{aligned}
& R_{\text {adj. }}^{2}=0.999 \quad D W=1.864 \quad E G=-6.558
\end{aligned}
$$

The $t$-values shown in brackets are only for information and cannot be used for statistical inferences about the significance of the individual variables, because the OLS estimates of the cointegration parameters are generally not normally-distributed. However, the adjusted $R^{2}$ of 0,999 indicates a very good fitting of the model to the observed data. The $D W$ statistics suggest that there is no first order autocorrelation. Furthermore, the null hypothesis of no cointegration relation of the $E G$ test can be rejected a significance level of $1 \%$, indicating that this equation can be interpreted as a long-term production function. The magnitudes of the coefficients of the indicator variables for the innovation output and the use of information and communication as well verify that the factors approximated by the indicator variables make contributions to real GDP that cannot be neglected. In a longterm view, output grows by roughly $0.1 \%$ if the patent stock increases by $1 \%$, and by roughly $0.12 \%$ if the effects captured by telephone calls increase by $1 \%$.

For the specification of the long-term labour demand function, we use a standard formulation whereby the number of persons employed depends on real GDP, real labour costs per person employed and a time trend (cf. e.g. HANSEN, 1992 and 1993). Including 
the already mentioned dummy variables and an error term $u_{2 t}$, the OLS estimation for the logarithmic form yields:

$$
\begin{aligned}
l_{t}= & -4.429+0.716 y_{t}-0.482 \ln \left(\left(W A G E_{t} / P G D P_{t}\right) * 100\right)-0.007 t \\
& (-5.40) \quad(9.75) \quad(-9.79) \\
& +0.021 D O C+0.030 D 80+0.182 D G U+0.015 D 99+u_{2 t} \\
& (2.86) \quad(4.12) \quad(11.78) \quad(1.98) \\
R_{a d j .}^{2}= & 0.997 \quad D W=0.931 \quad E G=-3.442 .
\end{aligned}
$$

The adjusted $R^{2}$ indicates a very good fitting for this model as well. Furthermore, based on the EG statistic it can be concluded at a significance level of $5 \%$ that the employment demand function is also a cointegration relation. As expected, real GDP has a positive impact on employment, while the influence of real wages is negative. The negative sign of the trend coefficient is in accordance with other estimations of labour demand functions for Germany (cf. again HANSEN, 1992 and 1993).

We also used a standard specification of a demand function for the long-term demand for telephone calls, with the number of telephone calls depending positively on income and negatively on the real price of telecommunication services. Again after the inclusion of some dummy variables and an error term $u_{3 t}$, OLS estimation of the logarithmic form gives:

$$
\begin{aligned}
& t c_{t}=\underset{(-12.03)(28.98)}{-18.267}+\underset{(-1.80)}{2.095} y_{t}-\underset{(216}{0} \ln \left(\left(P T E L_{t} / P G D P_{t}\right) * 100\right) \\
& +0.136 D 81-0.190 \mathrm{DGU}+0.128 D 99+u_{3 t} \\
& R_{\text {adj. }}^{2}=0.996 \quad D W=1.031 \quad E G=-4.118 \text {. }
\end{aligned}
$$

The explanatory power of this equation is also very high. Moreover, the EG statistics show a cointegration relation at a significance level of $1 \%$. The high income elasticity of the demand for telephone calls is especially conspicuous. If real income grows by $1 \%$, the demand for telephone calls increases by roughly $2.1 \%$. Furthermore, the positive sign of the dummy variable D99 shows that telecommunication liberalisation has positive effects on demand, which go beyond a pure price effect.

\subsection{Estimation of the Dynamic Simultaneous Error Correction Model}

Subsequent to the determination of economically well-founded long-term relationships, a dynamic simultaneous-equations model was specified, which, on the one hand, captures short-term dynamics, and, on the other hand, includes error correction terms to take the long-term relations into account. Therefore, each equation for the first differences of the endogenous variables - real GDP, number of persons employed and number of telephone calls - contains deviations from the long-term equilibrium relationships lagged for one year in addition to the - partly lagged - first differences of the explanatory variables (i.e., the lagged residuals of the respective cointegration relation). Three-step least squares is applied to estimate the simultaneous-equations model subject to all available information. This gives the following model, which forms the basis for the further analyses and simulations: 
Production function:

(6)

$$
\begin{aligned}
& \Delta y_{t}=0.002-0.864 e c m_{t-1}^{y}+0.346 \Delta y_{t-1}+0.448 \Delta k_{t} \\
& \begin{array}{llll}
(0.42) & (-2.61) \quad(1.86) \quad \text { (1.98) }
\end{array} \\
& +0.317 \Delta l_{t}-0.164 \Delta l_{t-1}+v_{1 t} \\
& \text { (3.43) } \quad(-1.63) \\
& R_{\text {adj. }}^{2}=0.753 \quad D W=1.864
\end{aligned}
$$

\section{Labour demand:}

(7)

$$
\begin{aligned}
\Delta l_{t}= & -0.008-0.312 \mathrm{ecm}_{t-1}^{l}-0.101 \Delta l_{t-1} \\
& \quad(-2.84) \quad(-2.16) \quad(-2.33) \\
& -0.513 \Delta \ln \left(\left(W A G E_{t} / P G D P_{t}\right) * 100\right)+0.538 \Delta y_{t}+0.256 \Delta y_{t-1} \\
& (-3.72) \quad(3.597) \quad(3,02) \\
& +0.020 \Delta D 80+0.198 \Delta D G U+v_{2 t} \\
& (2.93) \quad(7.05) \\
R_{\text {adj. }}^{2}= & 0.978 \quad D W=1.289
\end{aligned}
$$

Demand for telephone calls:

$$
\begin{aligned}
& \Delta t c_{t}= 0.034-0.487 e c m_{t-1}^{t c}+0.311 \Delta t c_{t-1}+0.522 \Delta y_{t}-0.305 \Delta y_{t-1} \\
&(3.23)(-4.20)(3.12)(-1.62) \\
&-0.258 \ln \left(\left(P T E L_{t} / P G D P_{t}\right) * 100\right)+v_{3 t} \\
&(-2.76) \\
& R_{a d j .}^{2}=0.476 \quad D W=2.163 .
\end{aligned}
$$

The fit of the equations of the error correction model to the observed data is also good, or for the demand function for telephone calls at least at the usual level. Furthermore, the error correction terms are in all three equations highly significantly different from zero, as the $t$-values within the brackets indicate, and they show a negative sign. Thus, there is actually an adjustment to their respective long-term equilibrium path. The explanatory variables in first differences, which capture the short-term dynamics, show the expected signs. In the production function, increases in the capital stock as well as in employment (the sum of the coefficients for the change of the number of persons employed is positive) also lead in the short run to an increase of GDP. Analogously, a rise in real GDP also leads in the short run to an increase of labour demand as well as an increase in the demand for telephone calls. Conversely, price variables (real wages and the real price for telecommunication services) also have negative effects on these respective equations in the short run. It is obvious that the indicator for the innovation output - the stock of patents and the number of telephone calls as a proxy variable for the whole indication filed for the use of information and communication (i.e., knowledge diffusion) mainly have long-term effects, since their first differences do not appear in the production function. However, this 
can be expected intuitively as well as from the viewpoint of economic theory (e.g., on the basis of new growth theory).

\subsection{Selected Scenarios}

The dynamic, simultaneous macro model presented above can be used for ex-post analyses on the one hand and for ex-ante simulations on the other. The simplest form of an ex-post analysis (i.e., an analysis within the estimation period) is a dynamic ex-post forecast, which provides information about the dynamic properties of the model. For such a forecast, the historical values of the exogenous variables are used, but the values of lagged endogenous variables are taken from the previous forecasts. If there is already a stronger deviation between the actual and forecasted values of the endogenous variables at the beginning of the observation period or at a later point in time as well, the ex-post forecasts will drift apart more and more from the actual values over the whole further observation period, because these errors will multiply due to the dynamics taken into account. Then the model is unsuited for ex-ante forecasts as well as simulations.

Scenario 1: From 1960 to 2000, the nominal price index for telecommunication services (PTEL) was permanently below $20 \%$ of the actual values.

In addition to the ex-post forecast, a simple ex-post scenario was carried out, in which it is assumed that the nominal price index for telecommunication services (PTEL) from 1960 to 2000 was permanently below $20 \%$ of the actual values. Figure 1 shows the development of the actual and forecasted values as well as the results from the simulation run. Comparing the actual values and the forecasts, there is clearly a very good fit for the telephone calls and real GDP, which points to the good dynamic properties of the model. Basically, the trend in development of employment is also reproduced adequately. However, temporary events like the first German crisis of 1967 and the fall of employment after German unification in the second and third quarter of the nineties are not recognized in this variable. Scenario 1 shows that permanently lower telecommunications costs would have been an important impulse for higher real income and more employment.

Figure 2 shows the percentage deviations between the dynamic ex-post forecasts and scenario 1. According to that, a permanent decrease of the price for telecommunication services by $20 \%$ leads to faster growth in the number of telephone calls, real GDP and employment in the early stages. However, this growth effect declines continually and converges towards zero, so that there is finally only a level effect, which is however considerable with respect to its magnitude. Since the mid-nineties, the number of telephone calls has been $15 \%$ higher than for the dynamic ex-post forecasts, real GDP $4.47 \%$ and the number of persons employed 3.18\%. 
Figure 1: Dynamic ex post forecasts and simulations (scenario 1) for the endogenous variables
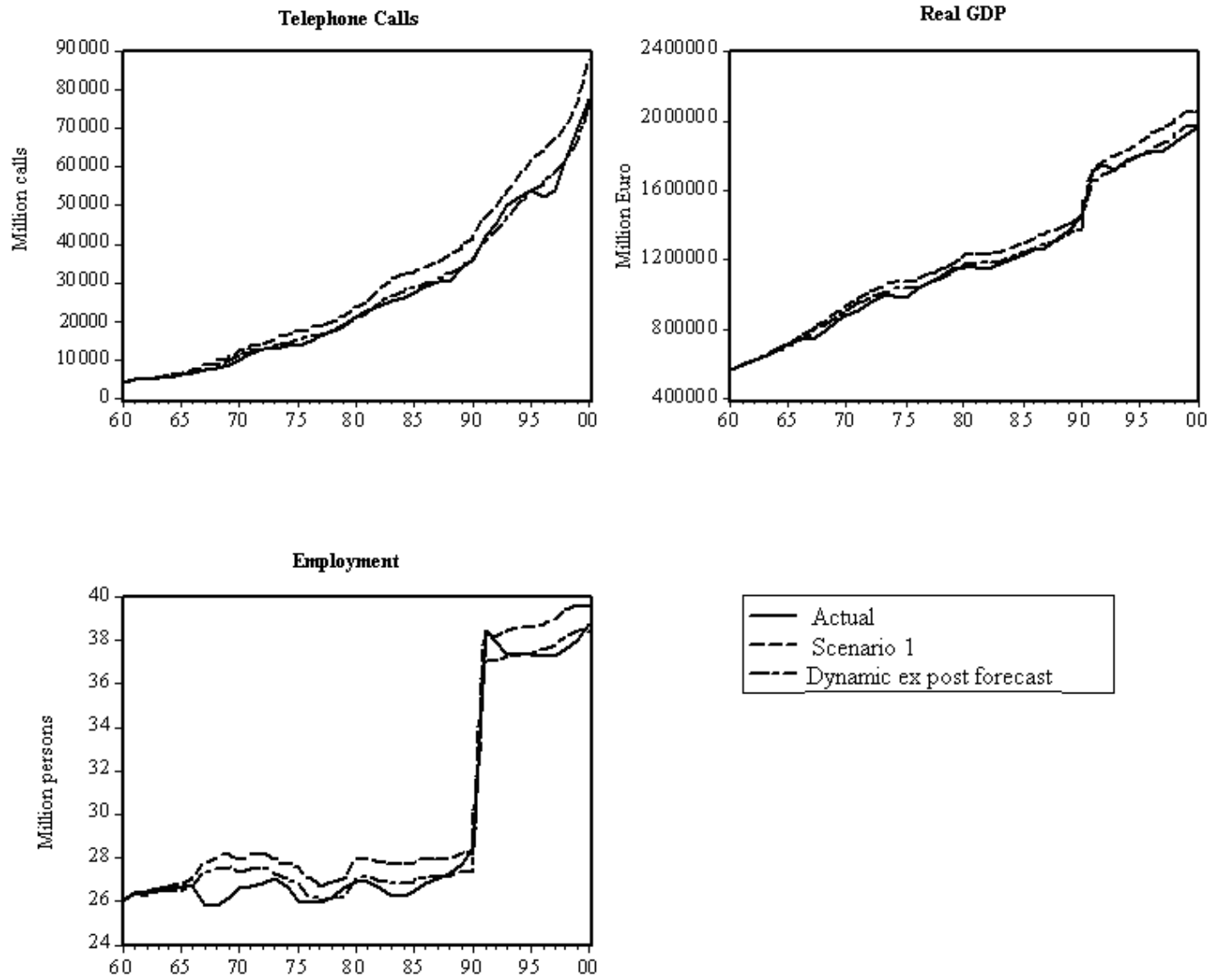

Ex-post simulations can lead to interesting conclusions for economic policy, and they show the magnitude of the effects of the measures of economic policy, but in the centre of the analysis is the simulation of alternative development paths for the future up through 2010. For not taking the assumptions on which the scenarios are based arbitrarily, expert opinions are used for their justification. 
Figure 2: Scenario 2: Effects of a permanent cut in PTEL by $20 \%$ (percentage deviations from dynamic ex post forecasts)
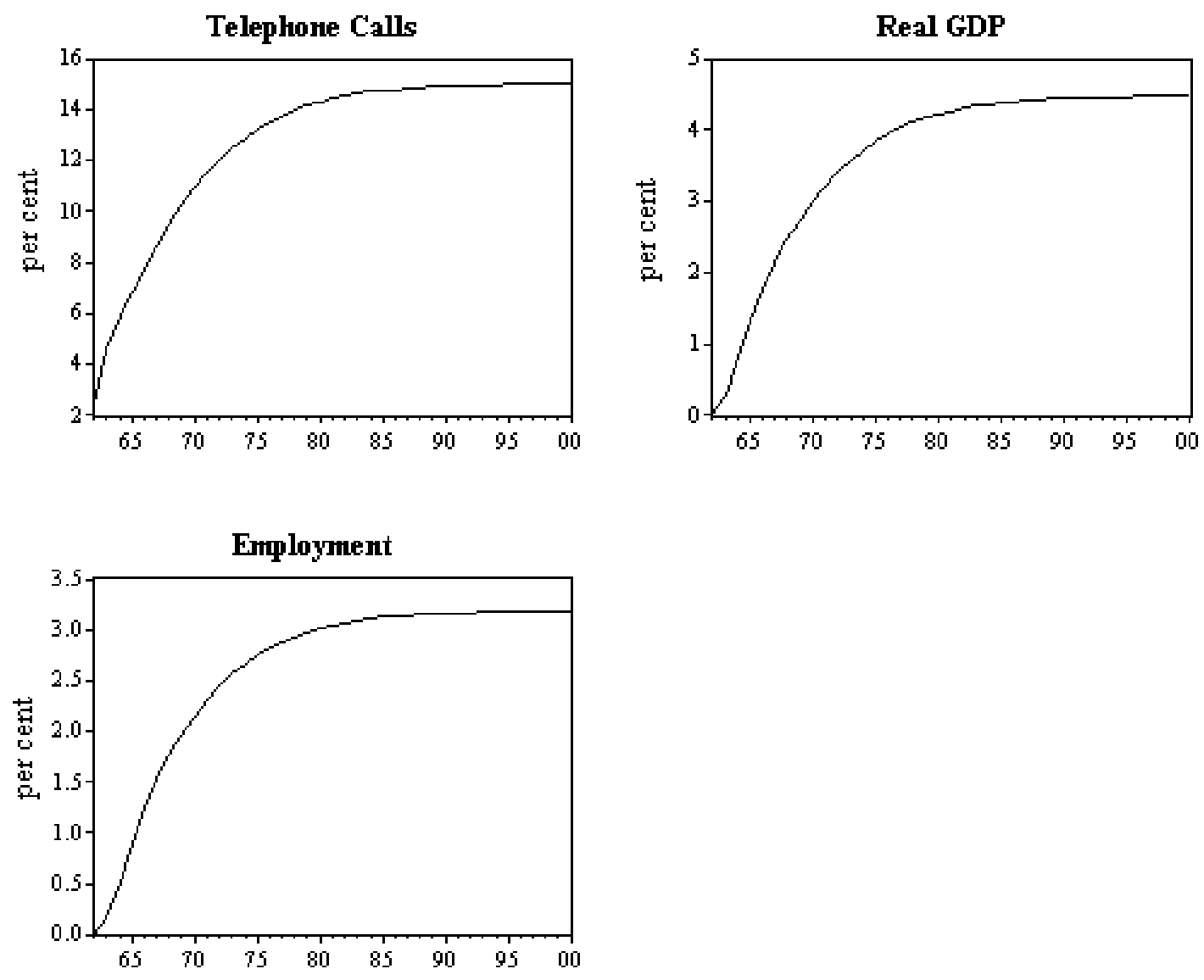

Five ex-ante scenarios were developed in this manner. For all these scenarios, we assume that the other exogenous variables follow rather conservative development paths based on their trend development within the last available ten years (partly taking into account the forecasts for 2004 of DG II of the European Commission. Thus, the capital stock increased on average by $1.83 \%$ from 1995 to 2004. This development was prolonged until 2010. We proceeded analogously for the wages, which grew on average yearly by $1.51 \%$ from 1994 to 2003, and the price index of GDP, which increased yearly on average by $0.86 \%$ from 1995 to 2004 . Since the patent stock as a further exogenous variable shows no clear trend and stays roughly - after a clear decrease in the first half of the nineties - on the same level, we assume zero growth for this variable through 2010. Furthermore, the development of real GDP was exogenised for the years 2001 until 2003 in all ex-ante simulations, because the exogenous shocks in this period would lead to a clear overestimation of actual growth within a model immanent forecast - as in all other econometric models as well.

Based on these fundamental assumptions which hold for all ex-ante simulations, we have looked at the following scenarios based on expert opinions:

Scenario 2: The price index for telecommunications services (PTEL) increases by 2\% p.a. between 2003 and 2010.

The background for scenario 2 is that there was a slight increase in the price index for telecommunication services in 2002, for the first time since 1996. A continuation of this 
pessimistic trend is considered possible based on the following arguments: Prices for user access are used to cross-subsidize digital services. It is true that pure transmission costs for telecommunications are falling, but the respective cost reductions are not fully passed on to the user. Rather there is a tendency to combine increased access prices with lower per minute or per bit prices. Thus one should not overlook that voice services - partly already based on the internet protocol (naturally in the case of UMTS) - have increasingly become a commodity while voice telephony remains the cash cow of leading operators.

Scenario 3: The price index for telecommunications (PTEL) stays at the level of 2002

This scenario can be considered a neutral point of reference: The nominal price stays constant but as there is a rise of the general price level, the real price of telecommunications falls by $0.86 \%$ p.a.

Scenario 3: The price index for telecommunications (PTEL) will fall by 4\% p.a. in the period between 2003 and 2010.

This assumption seeks to extend the development observed since 1998 while ignoring the slight rise of telecommunications costs in 2002 (i.e., that is the price development of 2002 is considered an irrelevant outlier). The argument for this scenario is basically the opening up of markets in local telecommunications (as of 2003). This should lead to intensified price competition which translates into falling prices for users. Hence the potential for cost reductions associated with new technologies (e.g., VOIP/internet-based telecommunications) is passed on to the user. This scenario also takes into account the potentially growing role of newcomers in telecommunications and the associated intensification of price competition. Voice services will become a quasi-commodity once several players become active in the market. The rising role of mobile communications also puts pressure on operators in the fixed-line business.

The two other scenarios are not based on the assumption of an exogenous variable price index for telecommunications services but on exogenous pre-determined adjustment paths for the endogenous variable, 'number of telecommunications calls'. We are looking here at a pessimistic and an optimistic variant.

Scenario 5: The number of telecommunication calls (TC) increases by $3 \%$ p.a. in the period from 2001 to 2010.

This rather pessimistic case assumes a rather modest rise in the number of calls. Arguments for such a scenario are based on the assumption that the use of both broadband access and of flat rate online offers are not taken up on a broad scale. Moreover, there are substitution effects in the sense that online users switch to broadband offers whereby pricing is often based on a flat rate. Such users - exploiting a flat rate - will not show up in the form of a rising number of calls.

Scenario 6: The number of telecommunication calls (TC) will rise by $7 \%$ in the period from 2001 to 2010.

This optimistic scenario assumes that the number of telecommunication calls will rise strongly, including a rising number of online users. Broadband and flat-rate dynamics cannot keep pace with the fast growth of new online users. Hence a large number of online users will use the internet via a standard model or ISDN channels even in 2010. As a critical caveat, one should consider that a long run growth rate of $7 \%$ is an extreme assumption as saturation processes are not taken into account (approaching a saturation point implies a decline of growth rates over time). 
The results of the simulations for all ex-ante scenarios are shown in the following table. We indicate the annual growth rates for the three endogenous variables of the model. As regards the number of telecommunication calls, the pessimistic and the relatively neutral scenarios for price dynamics of telecommunication services will only translate into either low or modest growth, approaching roughly the exogenous growth rate of $3 \%$ after 2006/2007. The dynamics are different for the case of a fall of prices by $4 \%$. Over time there will be a strong increase in the number of calls with the growth rate reaching $5.6 \%$ in 2010. However, even this strong fall in the telecommunications price does not translate into a similar case as the exogenously-given $7 \%$ in the number of calls.

As regards the growth of the real GDP, all scenarios except for scenario 6 - meaning exogenous growth of calls by 7\% p.a. - amount to achieving a growth rate of $2 \%$ in 2004 . This figure is consistent with the projection of DGII of the European Commission which also foresees gains of $2 \%$. As regards the pessimistic and the relatively neutral scenario, the growth of real GDP would decline slightly up through 2007 but would thereafter increase until 2010 (not having achieved the growth rate for 2004). A different perspective holds in scenario 4. Here we can see that output growth dynamics at the end of the decade are slightly higher than in 2004 with an interim period of modest growth rate.

Table 1: Results of the ex ante simulations (percentage growth rates of the endogenous variables)

\begin{tabular}{|c|c|c|c|c|c|c|c|}
\hline Scenario & 2004 & 2005 & 2006 & 2007 & 2008 & 2009 & 2010 \\
\hline \multicolumn{8}{|c|}{ Telephone calls } \\
\hline 2. PTEL +2 \% p. a. & 0.4 & 1.5 & 2.5 & 2.8 & 2.8 & 2.6 & 2.6 \\
\hline 3. PTEL konstant & 1.1 & 2.1 & 3.2 & 3.6 & 3.6 & 3.5 & 3.6 \\
\hline 4. PTEL -4 \% p. a. & 2.5 & 3.6 & 4.7 & 5.3 & 5.4 & 5.5 & 5.6 \\
\hline 5. $T C+3 \%$ p. a. & 3.0 & 3.0 & 3.0 & 3.0 & 3.0 & 3.0 & 3.0 \\
\hline 6. $T C+7 \%$ p. а. & 7.0 & 7.0 & 7.0 & 7.0 & 7.0 & 7.0 & 7.0 \\
\hline \multicolumn{8}{|c|}{ Real GDP } \\
\hline 2. PTEL +2 \% p. a. & 1.9 & 1.6 & 1.2 & 1.2 & 1.3 & 1.4 & 1.4 \\
\hline 3. PTEL konstant & 2.0 & 1.7 & 1.4 & 1.4 & 1.5 & 1.6 & 1.7 \\
\hline 4. PTEL -4 \% p. а. & 2.1 & 2.0 & 1.8 & 1.9 & 2.0 & 2.2 & 2.3 \\
\hline 5. $T C+3 \%$ p. a. & 1.8 & 1.8 & 1.6 & 1.6 & 1.5 & 1.6 & 1.5 \\
\hline 6. $T C+7 \%$ p. a. & 3.2 & 3.5 & 3.2 & 3.0 & 2.9 & 2.8 & 2.8 \\
\hline \multicolumn{8}{|c|}{ Employment } \\
\hline 2. $P T E L+2 \%$ p. a. & 0.0 & 0.2 & -0.1 & -0.2 & -0.1 & -0.1 & 0.0 \\
\hline 3. PTEL konstant & 0.0 & 0.3 & 0.0 & 0.0 & 0.0 & 0.1 & 0.2 \\
\hline 4. PTEL -4 \% p. а. & 0.1 & 0.5 & 0.3 & 0.3 & 0.4 & 0.5 & 0.6 \\
\hline 5. $T C+3 \%$ p. a. & -0.1 & 0.3 & 0.1 & 0.1 & 0.1 & 0.1 & 0.1 \\
\hline 6. $T C+7 \%$ p. a. & 0.7 & 1.5 & 1.3 & 1.2 & 1.1 & 1.0 & 1.0 \\
\hline
\end{tabular}

The scenarios with exogenous growth of telecommunication calls show that a growth rate of $3 \%$ will not suffice in the long run to maintain the growth rate of $1.8 \%$ in 2004 . An exogenous growth rate of calls by $7 \%$ would result in higher growth which, however, would reduce in the second half of the decade. As a caveat, one should point out that such high growth rates are plausible only if the share in residential phone calls would rise overproportionately, a case which is not unlikely given the enormous dynamics of mobile 
telecommunications. However, such a structural change would violate the implicit assumption of the model, namely that there is a constant ratio of residential calls to business calls. It also is noteworthy that the scenarios indicate that after a slight increase in the price of telecommunications services, there will be - after a slight employment growth in 2005 -slightly negative employment effects after 2006. A constant telecommunications price index implies a slight increase in employment, while a fall of the telecommunications price index corresponds with higher employment growth. A fall of the (relative) price index by $4 \%$ p.a. would therefore translate into considerable cumulated employment growth: 200,000 by 2006; 450,000 by 2008 and 760,000 by 2010 .

Table 2: Employment effects in alternative ex-ante simulations (absolute deviations from scenario 3: PTEL constant)

\begin{tabular}{lclccccc}
\hline \hline Scenario & 2004 & 2005 & 2006 & 2007 & 2008 & 2009 & 2010 \\
\hline & \multicolumn{7}{c}{ Employment (in mill. Persons) } \\
2. PTEL +2 \% p. a. & -0.01 & -0.05 & -0.10 & -0.15 & -0.22 & -0.29 & -0.36 \\
4. PTEL -4 \% p. a. & 0.03 & 0.10 & 0.20 & 0.32 & 0.45 & 0.60 & 0.76 \\
5. TC +3 \% p. a. & -0.04 & -0.05 & 0.00 & 0.05 & 0.06 & 0.03 & -0.01 \\
6. $T C+7$ \% p. a. & 0.25 & 0.72 & 1.24 & 1.71 & 2.12 & 2.47 & 2.79 \\
\hline
\end{tabular}

\section{Policy Implications}

The empirical analysis suggests that a long run fall of the telecommunications prices will stimulate the use of information as an input in the production function and hence stimulate the diffusion process. At the bottom line, one may expect higher output and higher employment which would be important not only for Germany but for other OECD countries with high unemployment as well. From this perspective, it is important to focus on key issues in the regulation of telecommunications. Sustained competition can be expected to bring about both static and dynamic efficiency gains. However, the dominant position of the incumbent telecommunications operator, the former national monopoly operator, raises some doubts about the viability of competition (WELFENS, 2003; 2005a; 2005b). While it is true that regulators in some countries (e.g., Germany and Austria) have introduced pre-selection options as a means to open up competition in fixed line telephony in the late 1990s, it also is true that the incumbent operators have reacted. By offering bundled services, incumbent operators have tried to shift market power from the local access market in which they strongly dominate towards other market segments such as long distance calls and international calls. At the same time broadband technology is expanding in the US and Europe so that the quality of digital services will improve while relative prices could continue to fall. From the perspective of the macroeconomic production function one should emphasize that only part of the digital services provided stand for factor inputs; a considerable share has to be classified as household consumption.

Market opening up - as required by the European Commission - and privatization of the respective incumbent operator in most EU countries have stimulated the expansion of fixed network telecommunications services. Fixed-line telecommunications indeed should be regulated to the extent that newcomers in the market face the problem that the incumbent operator can get access to customers only through its local network; only in 
countries or regions with cable TV as an alternative network one may consider competition problems as rather small - e.g. the case of the Netherlands. The regulator should make sure that there is reasonable access to the network of the incumbent operator and that prices for the respective services are based on long run costs. Adequate bottleneck regulation (i.e., cost-oriented regulation of essential facilities) is crucial for sustained competition in all network sectors in which falling average and marginal costs are combined with a considerable role of sunk costs. (The latter impair market entry and thus reduce prospects for potential competition.) As local access prices have increased in 2004 for the first time in the post-1998 market in Germany, there is evidence that there might be no sustained fall in the price of telecommunications services.

It will remain an important challenge for the regulator that sustained competition be enforced and that digital innovation dynamics be reinforced (Welfens/Weske, 2006). The tendency of product bundling which has gained importance after a first liberalization stage makes market entry for new firms more costly and more risky so that potential competition is losing significance. At the same time there is a doubtful tendency of the German regulator to inflate the number of prices which are subject to ex-ante regulation. From a theoretical perspective, one should only have strict ex-ante price regulation in the field of essential facilities. All other areas should be fully liberalized. There is, however, the problem that the bundling of various services - those which are regulated and those which have not been regulated so far - raises difficult problems for the regulator. To the extent that bundling is considered a normal element of competition (hence the type of bundling indeed could have occurred under competition), the regulator should not impair bundling. Yet there is an issue when the dominant operator uses high profits from the regulated markets to cross-subsidize non-regulated other digital services markets. Predatory pricing and dumping thus could be temporary problems.

Regulatory institutions and rules matter for economic policy and for investors. The EU has established a rather consistent framework regulation which imposes broad guidelines for various sub-markets in fixed-line telephony. National regulators still have considerable autonomy and have pursued different approaches in digital regulation which to some extent reflect national policy preferences, size of the market and willingness to accept market forces in a field where there is still a role for universal services. In the case of the telecommunications sector, it is important that the regulator not impose artificial costs/risks on market actors, since a rise in services prices would follow. The regulator should indeed limit itself to a strict bottleneck regulation and not impose restrictions which undermine the incentive for market entry on the part of domestic or foreign newcomers. Pending new telecommunications regulations in the US and Germany in 2006 underlines the necessity to emphasize sustained competition in telecommunications.

Even if the regulator adopts an efficiency-enhancing regulatory policy, positive employment effects require complementary institutional elements. As regards the link between output dynamics and employment, it is well known that labour markets in Germany and some other EU countries are relatively inflexible. If fear of accelerated structural change should encourage trade unions to even more strongly emphasize the protection of insiders in collective bargaining, the link between potential output growth and employment growth could weaken. It is obvious that modern digital technology offers a broad array of new options for organizing research \& development, production, financing and marketing more flexibly, but more flexibility will require organizational changes in most firms. If resistance against such organizational learning is high, the potential benefits of accelerated diffusion in the digital economy cannot be reaped. Measures which further tighten adjustment options in the labour market are inadequate. 
Finally, one may notice that the digitization of the economy creates new opportunities for both digital international trade and for new forms of digital international outsourcing. To the extent that cheaper international telecommunications calls as well as the internet mainly stimulate trade in Europe, one should not anticipate new complications for countries with employment problems. However, if digitization should stimulate net foreign direct investment outflows, the combination of a slow-down in capital accumulation in the source country and the faster international diffusion of knowledge could impair high wage countries' prospects for positive output and employment effects from falling (national and international) telecommunications prices. 


\section{References}

Audretsch, D.; Welfens, P. J.J., eds. (2002), The New Economy and Economic Growth in Europe and the US, Berlin et al.: Springer

Bayoumi, T.; Laxton, D.; Pesenti, P. (2004), Benefits and Spillovers of Greater Competition in Europe: A Macroeconomic Assessment, Federal Reserve Bank of New York Staff Paper No. 182, New York.

Budd, A., Hobbis, S. (1989), Output growth and measure of technology, Discussion paper, London Business School Centre for Economic Forecasting, July 1989.

Budd, A., Hobbis, S. (1989a), Cointegration, technology and the long-run production function, Discussion paper, London Business School Centre for Economic Forecasting, July 1989.

Canning, D. (1999), Telecommunications and aggregate output, CAER II Discussion Paper No. 56, Harvard Institute for International Development, Cambridge, MA.

Coe, D. T. and Moghadam, R. (1993), Capital and trade as engines of growth in France, in: IMF Staff Papers, 40, pp. 542 - 566.

Cronin, F. J.; Colleran, E. K.; Herbert, P. L. et. al. (1993), Telecommunications and growth: The contribution of telecommunications infrastructure investment to aggregate and sectoral productivity, in: Telecommunications Policy, pp. 677 - 690.

Cronin, F. J.; Parker, E. B.; Colleran, E. K. et al. (1993), Telecommunications infrastructure investment and economic development, in: Telecommunications Policy, 415 - 430.

Falk, M.; Koebel, B.M. (2004), The impact of office machinery, and computer capital of the demand for heterogeneous labour, in: Journal of Labour Economics, Vol. 11 (2004), 99-117.

Grupp, H. (1997), Measurement and Explanation of Technological Change/Messung und Erklärung des technischen Wandels, Berlin.

Hansen, G. (1992), Macroeconomic Modelling: an Update/Makroökonomische Modellierung heute, in: RWI-Mitteilungen 43, 287 - 300.

Hansen, G. (1993), Quantitative Economic Analysis/Quantitative Wirtschaftsforschung, Munich.

Jorgensen, D.W.; Stiroh, K. (2000), Raising the speed limit: U.S. economic growth in the information age, Brookings Papers on Economics Activity (2000), U.S. economic growth and development at industry level, American Economic Review, Vol. 90, No. 2

Jorgensen, D.W.; Ho, M.S.; Stiroh, K.J. (2002), Growth of US Industries and Investments in Information Technology and Higher Education, Harvard University, mimeo.

Jungmittag, A. (2002), Innovation dynamics in the EU: Convergence or divergence - A cross-country panel data analysis, Paper presented at the international conference „Dynamics, Economic Growth, and International Trade, VII (DEGIT-VII) in Cologne, May 24-25, 2002, Diskussionsbeitrag Nr. 96, Europäisches Institut für internationale Wirtschaftsbeziehungen (EIIW), Potsdam. 
Jungmittag, A.; Blind, K.; Grupp, H. (1999), Innovation, standardisation and the long-term production function: A cointegration analysis for Germany $1960-1996$, in: Zeitschrift für Wirtschafts- und Sozialwissenschaften 119, pp. 205 - 222.

Jungmittag, A.; Welfens, P. J.J. (1996), Telecommunications, Innovation and the Longterm Production Function/Telekommunikation, Innovation und die langfristige Produktionsfunktion: Theoretische Aspekte und eine Kointegrationsanalyse für die Bundesrepublik Deutschland, .Discussion Paper No. 20, Europäisches Institut für internationale Wirtschaftsbeziehungen (EIIW), University of Potsdam.

Karunaratne, N. D. (1997), High tech innovations, growth and trade dynamics in Australia, in: Open Economies Review, Vol. 8, pp. 151 - 170.

Mankiw, N. G.; Romer, D.; Weil, D. N. (1992), A contribution to the empirics of economic growth, Quarterly Journal of Economics, Vol. 107, pp. 407 - 438.

Röller, L. H.; Waverman, L. (1996), Telecommunications infrastructure and economic development: A simultaneous approach, WZB discussion paper FS IV 96 - 16.

Röller, L. H.; Waverman, L. (1996a), The impact of telecommunications infrastructure on economic development, in: Howitt, P., ed., The implications of knowledge-based growth for micro-economic policies, Calgary.

Van Ark, B.; Piatkowski, M. (2004), Productivity, Innovation and ICT in Old and New Europe, International Economics and Economic Policy, Vol. 1, 215-246.

Welfens, P.J.J. (2003), Interneteconomics.net, Heidelberg and New York, $2^{\text {nd }}$ edition forthcoming in 2007.

Welfens, P.J.J.; Zoche, P.; Jungmittag, A. et al. (2005), Internet Economy 2010/ Internetwirtschaft 2010 (study for the Federal Ministry of Economics and Labour), Heidelberg: Physica.

Welfens, P.J.J.; Weske, M., eds. (2006), Digital Economic Dynamics. Innovations, Networks and Regulations, Heidelberg: Springer. 